on demand. It may not matter that GPs have traded a bit of autonomy for the greater good when clinical freedom is now so difficult to defend; or that general practice mainly provides Monday to Friday daytime care in the NHS and many other healthcare systems.

The research on the dangers of stress and poor morale has convinced doctors, and more importantly their negotiators, that quality of life needs to be taken more seriously. What happens in the NHS is important internationally as even marketdriven healthcare systems look to it for trends and ideas. As there seems to be much in the 2004 contract for GPs it will become a reference point for doctors in other international healthcare systems.

Most governments seem to dread negotiations on pay and rations with doctors, as every new contract seems to come in over the dead bodies of the profession, who often discover well-hidden merits in the existing contract that a previous generation opposed. The merits in the 2004 contract for doctors and populations are not at all hidden, but a government may easily put aside its dread of doctors and decide to rebalance the benefits specifically in favour of the patient.

In the Culture of Contentment, ${ }^{13}$ Galbraith wrote about how the selfinterested perspective of the well off could shape modern political and economic culture in the short term. A number of troubling questions emerge from a newfound contentment. Do the contented innovate, question, and advocate for patients or themselves? Is it possible to have some fellow feeling for the trials and tribulations of patients from a base of contentment? Will a contented profession with diminished autonomy be easily driven off course by externally set targets and politicians hell bent on improving the health of the nation for electoral advantage? For sure GPs in Denmark would like a bit more contentment - for now.

\section{Thomas O'Dowd}

Professor of General Practice,

Trinity College, Dublin.

\section{REFERENCES}

1. Cartwright A. Patients and their doctors: a study of general practice. London: Routledge \& Kegan Paul, 1967.

2. Cartwright A, Anderson R. General practice revisited. A second study of patients and their doctors. London: Tavistock, 1981.

3. Maslach C, Schaufeli WB, Leiter MP. Job burnout. Annu Rev Psychol 2001; 52: 397-422.

4. McManus IC, Winder BC, Gordon D. The causal links between stress and burnout in a longitudinal study of UK doctors [research letter]. Lancet 2002; 359: 2089-2090.

5. O'Dowd TC. To burn out or to rust out in general practice [editorial]. J R Coll Gen Pract 1987; 37(300): 290-291.

6. Gilliland AEW, Sinclair H, Cupples ME, et al. Stress and morale in general practice: a comparison of two health care systems. Br J Gen Pract 1998; 48 1663-1667.

7. Bosma H, Marmot MG, Hemingway $\mathrm{H}$, et al. Low job control and risk of coronary heart disease in Whitehall II (prospective cohort) study. BMJ 1997; 314(7080): 558-565.

8. Aboa-Eboulé C, Brisson C, Maunsell E, et al. Job strain and risk of acute recurrent coronary heart disease events. JAMA 2007; 298(14): 1652-1660.

9. Sibbald B, Bojke C, Gravelle H. National survey of job satisfaction and retirement intentions among general practitioners in England. BMJ 2003; 326: 22.

10. Whalley D, Gravelle, Sibbald B. Effect of the new contract on GPs' working lives and perceptions of quality of care: a longitudinal survey. Br J Gen Pract 2008; 58(546): 8-14.

11. Brøndt A, Sokolowski I, Olesen F, Vedsted P. Continuing medical education and burnout among Danish GPs. Br J Gen Pract 2008; 58(546): 15-19.

12. McDonald R, Harrison S, Checkland K, et al. Impact of financial incentives on clinical autonomy and internal motivation in primary care: ethnographic study. BMJ 2007; 334: 1357-1359.

13. Galbraith JK. The culture of contentment. Boston: Houghton Mufflin Company, 1992.

DOI: 10.3399/bjgp08X263730

\section{ADDRESS FOR CORRESPONDENCE}

\section{Thomas O'Dowd}

Department of Public Health and Primary Care, Trinity College Centre for Health

Sciences, Adelaide and Meath Hospitals, Tallaght, Dublin 24, Ireland.

E-mail: todowd@tcd.ie

\title{
Work patterns in UK general practice: turning the clock back?
}

The 1966 contract for UK GPs can be judged to have brought about a remarkable renaissance in primary care. For those unfamiliar with the history, it is worth recalling what it was like before then. Most practices were single-handed, and there was no incentive to invest in staff or premises. GPs were memorably faced with the choice of maximising their income by looking after large lists of patients, or having smaller lists, employing staff, and investing in their premises and surviving on lower incomes. Significantly, the 1966 contract marked the end of the 'assistant with a view'. These were doctors unable to get a practice of their own, and employed by existing doctors 'with a view' to taking over the practice in due course. Such doctors ended up trapped, waiting for a partnership that came late or not at all, and working for another doctor at a lower rate of pay. The 1966 contract introduced a fee structure with a number of different elements, specifically rewarding doctors working in partnerships, providing generous arrangements for investing in premises, and reimbursement for employing staff.

Over time, much of this complex structure has been eroded, first with the 1990 contract, followed by personal medical services (PMS) contracts. The 2004 changes found in the new general medical services (GMS) contract significantly replaced contracts between the PCT and individual principals, with contracts with practices. Despite that, many of the changes since 1966 are here to stay. The performance management 
elements of the contract require sound practice management and a lot of support so that the future of practice managers and practice nurses seem assured in one way or another. However, it has also been accompanied by a resurgence in the numbers of salaried doctors.

On page 20 of this month's BJGP, Ding and colleagues describe their experience. ${ }^{1}$ They found salaried doctors to be more frequently found among older and younger doctors, and among female doctors, more likely to be working part-time and in practices with PMS contracts. The overall conclusion was that such posts had answered a significant need for doctors who wanted more flexibility and removed some of the constraints in the labour market for GPs. At the same time, their study confirmed earlier findings that salaried posts had signally failed to fulfil one of the earlier aims of attracting doctors to areas of greatest need.

It is interesting that the gender pattern has shifted. When salaried posts were introduced they were predominantly taken up by young male doctors. It is possible that the more generous incomes available since 2004 have made the salaried option less attractive to men, or that the terms and conditions coincide more closely with the way many women wish to work.

At the same time, anecdotal accounts of doctors emerging from postgraduate training schemes suggest a worrying trend. While there is no firm evidence, it looks as if established principals have discovered the advantages of engaging doctors employed on a salary below that of a partner, so that partnerships have become difficult to find. Modern employment law gives such salaried doctors much better protection than their pre-1966 ancestors, but there is no guarantee that they will ever proceed to partnerships. Not so much a return of the 'assistant with a view' as of a new animal, an assistant with no view at all.
At a time when general practice is once again proving popular as a career choice, and when the new curriculum has given greater certainty to postgraduate training, there is an irony that we may be producing a generation of doctors trained to a higher standard then ever before but without being able to offer appropriate career opportunities at the end of their training. Ding's paper shows very clearly that many doctors welcome the combination of flexibility and reduced commitment that they have as salaried doctors, and that the option may enable some to make a career in general practice who would otherwise be frightened off.

At the same time, the discipline cannot afford to lose those wishing to make a more substantial commitment, who will develop their practices and the profession as a whole, over their working lifetimes. If we are to sustain the familiar model of general practice, there is an urgent need to find out whether newly trained doctors are being frustrated in this way, and if so to devise a more neutral funding formula that can accommodate both kinds of ambition.

There is another major difference between 1966 and now. Before 1966 all general practice was a cosy world of Executive Committees and principals; now there is no certainty that employed doctors will be employed by other principals. Already a significant number of practices are being run by commercial enterprise employing GPs, and this trend looks set to expand. If a large part of the work is going to be done by salaried doctors, the arguments in favour of practices run by principals are weaker. For a salaried doctor, as for patients, it will make little difference if the practice is being run by a commercial company or by a partnership. The profession needs to consider whether the model that has been unchallenged until very recently is worth retaining. Perhaps the so-called independent contractor status has had its day.
However, before we consign it to the dustbin of history we should consider, if only for a moment, what we might be losing, if anything. Independence never looked very real with the NHS operating a near monopoly as customer, and now that the contract determines some of what we do we are looking more like government functionaries than ever before. In England (much more than in Scotland, Wales, and Northern Ireland), a highly-centralised government agency and a salaried profession could turn out to be a toxic and damaging combination. The NHS and, above all, the patients (and that's all of us) need a plurality of voices to inform health policy.

The Department of Health should welcome robust debate about the best way of providing high quality health care for the population, rather than appearing, as it has done of late, to listen only to its chosen confidants while dismissing outsiders as speaking only for their own vested interests. As a profession we need to retain an independent voice. How we are paid may not matter, but it is vital that we do not collude in silencing ourselves.

\section{David Jewell}

Editor, BJGP

\section{REFERENCE}

1. Ding A, Hann M, Sibbald B. Profile of English salaried GPs: labour mobility and practice performance.

Br J Gen Pract 2007; 58(546): 20-25.

DOI: 10.3399/bjgp08X263749

\section{ADDRESS FOR CORRESPONDENCE}

\section{David Jewell}

BJGP, Editorial Office,

14 Princes Gate, London SW7 1PU.

E-mail: David.Jewell@bristol.ac.uk

Discuss these editorials. Contribute and read comments about these editorials on the Discussion Forum: http://www.rcgp.org.uk/bjgp-discuss 